\title{
37 years of scientific activity in a Biochemistry Department in Brazil - patterns of growth and factors leading to increased productivity
}

\author{
URUBATÃ E. GOMES, DIOGO L. DE OLIVEIRA, LUCIANA C. BERTI, \\ OLAVO AMARAL, DIOGO O. SOUZA and SUSANA T. WOFCHUK \\ Universidade Federal do Rio Grande do Sul, Departamento de Bioquímica, \\ PPG em Educação em Ciências: Química da Vida e Saúde, Instituto de Ciências Básicas da Saúde, \\ Rua Ramiro Barcelos, 2600 (prédio anexo), 90035-003 Porto Alegre, RS, Brasil \\ Manuscript received on February 2, 2010; accepted for publication on May 17, 2010
}

\begin{abstract}
Scientific activity in Brazil has experienced an accelerated growth in the past decades, with an increase in productivity that greatly surpasses the international average. This growth has occurred mostly at the expense of centers of excellence in public universities, which account for the vast majority of the country's scientific output. The aim of this study was to evaluate the production of the Department of Biochemistry of a large public university in southern Brazil (Universidade Federal do Rio Grande do Sul), as well as to identify internal and external policies that have influenced this growing production profile. We have performed a historical analysis of the scientific output of this Department of Biochemistry, which accounts for a considerable share of the indexed scientific production at this university. By focusing on the temporal course of its growth and drawing correlations between scientific output and important events in the history of the Department of Biochemistry and of the Brazilian science policies, we concluded that internal factors (as the creation of a postgraduation program, collaboration among researchers, experienced abroad researchers, qualification of faculty members) and external factors (as investments in the postgraduate education, the establishment of national scientific policies, such as financial stimuli for productive researchers and evaluation systems) influence scientific productivity in Brazil.
\end{abstract}

Key words: scientific productivity, scientific growth profile, Biochemistry, UFRGS.

\section{INTRODUCTION}

The scientific production has been steadily growing in the world over the past decades, both in the developed and in the developing world. Some nations, however, have attracted attention for their explosive growth, which greatly surpasses the international average. Prominent among these, for example, are China and other Asian countries such as South Korea, Singapore and Taiwan, as well as fast-growing European nations such as Turkey, Portugal and Ireland (Granzel et al. 2006). Latin America's contribution to the world's

Correspondence to: Susana Tchernin Wofchuk E-mail: swofchuk@ufrgs.br scientific production has also been on the rise, increasing from $1.33 \%$ in 1981 to $1.8 \%$ in 1993 (Ayala 1995, Leta et al. 1998), reaching more than $3 \%$ in the XXI century. This rise has been attributed to increasing investments in the postgraduate education, increasing access to higher education (Schwartzman 2004) and to the return of democratic governments to a large part of the region (Granzel et al. 2006).

Two largest countries and main scientific "powerhouses" of the region, Brazil and Mexico, are in the forefront of Latin American scientific growth. Both have experienced a rapid growth in their number of publications from the 1970s onward, and have attracted attention to the study of factors influencing this growth 
(Velloso et al. 2004). Brazil alone was responsible for $1.6 \%$ of the world's scientific publications in 2003, after nearly tripling this share over the course of 15 years (Fig. 1) (Granzel et al. 2006), reaching to $2.02 \%$ in its contribution to world's scientific publication at 2007 (CAPES). The almost parallel increase in the number of postgraduate students is among the reasons cited for the growth of science in the case of Brazil are (Leta et al. 1998, De Meis et al. 2003a, De Meis 2003b), as well as the work of regulatory and fomenting agencies in monitoring, stimulating and rewarding scientific productivity within universities, even at times in which investment was low (Leta et al. 1998).

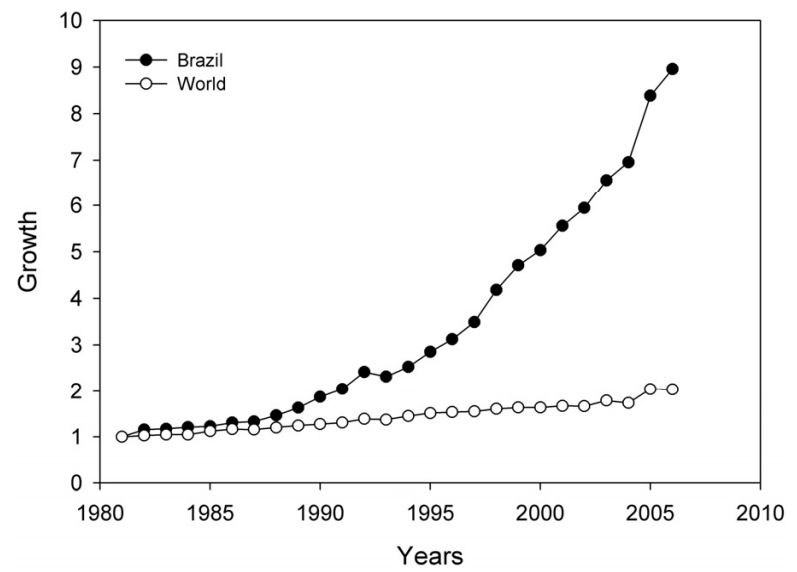

Fig. 1-Growth of Brazilian (black) and international (white) scientific publications from 1981 to 2006 . Growth is expressed as the ratio of the number of articles in a given year to the number of articles in 1981 (data obtained from the Brazilian Coordinating Agency for Advanced Training of High-Level Personnel - CAPES).

Other important events in the recent development of Brazilian sciences are the increased activity and importance of national fomenting agencies created in the 1950s and 60s, respectively the National Council for Scientific and Technological Development (CNPq) and the Coordinating Agency for Advanced Training of High-Level Personnel (CAPES) (De Meis and Longo 1990). This led to greater investments in the formation of human resources from the 1970s onwards, both on the graduate and post-graduate levels, as well as to the development of some large scale initiatives for financing the country's top research centers, especially after the mid-1990s (Leta et al. 2006), even though a total investment in science hasn't been consistent throughout the period (De Meis et al. 2003a)

Despite this growth science rise in Brazil has been asymmetric. Research in Brazil is still very much concentrated in a few universities, virtually all of them public, which produce the majority of research articles and possess the largest numbers of postgraduate programs (Velloso et al. 2004, Leta et al. 2006). Since the top 12 universities account for more than $70 \%$ of the country's scientific productivity, the reasons for the country's overall growth must be sought within this excellence centers. As previously shown, the number of faculty members in these universities has not risen significantly (Velloso et al. 2004), and public funding for science has been irregular (De Meis et al. 2003a). Therefore, other factors should be sought to account for this growth, including the rise in postgraduate programs (Leta et al. 1998) and other national and internal factors, which stimulate productivity.

In order to better understand how the combination of internal and external factors can drive the increase in scientific productivity observed in the Brazilian science, we have performed a case study in one of the most productive Department of Biochemistry in the country in the field of the Biological Sciences. Concentrating in Neuroscience, the Department of Biochemistry is one with the largest output of research articles in Universidade Federal do Rio Grande do Sul (the $5^{\text {th }}$ most productive university in the country) (Leta et al. 2006), and its growth significantly surpasses the national average.

The aim of this study was to evaluate and to analyze this increase in productivity, identifying internal and external factors and policies that have been determinant in the growth of this Department of Biochemistry, and might be therefore extendable to other research centers of excellence in Brazil.

\section{MATERIALS AND METHODS}

In order to evaluate the scientific production of the Department of Biochemistry at the UFRGS, we undertook a search for the productivity in periodicals by all faculty members listed as part of the Department of Biochemistry's faculty from its foundation in 1971 through the year of 2007. Data on dates of entry and retirement for 
each faculty member were obtained from the Department of Biochemistry's administration, along with the year in which their $\mathrm{PhD}$ titles were obtained. We also identified factors within the local and national scenarios thath have influenced this production.

The number of articles published by each active faculty member in every year was then obtained from the Curriculum Lattes database as registered in $\mathrm{CNPq}$, the main scientific regulation agency in Brazil. This database, in operation since 1999 , functions as the central reference for scientific production among Brazilian researchers, and must be filled by every researcher in order to submit scientific projects and apply for research grants. As such, it should contain the full list of publications by researchers in the country from the beginning of their careers onward the time. The number of theses supervised by the faculty members at the Department of Biochemistry was also obtained from Curriculum Lattes.

Total publication numbers were obtained by adding the numbers for each faculty member, taking care to avoid overlapping in the case of collaborations. Indexed articles were defined accordingly to the Journal Citation Report index from the Institute for Scientific Information (ISI), from which impact factors for each article were also drawn. Publications mentioned in the faculty's curriculum, but not in periodicals indexed by the ISI, were considered as non-indexed.

Data on local decisions (which we called internal factors) and external factors that could be related to the evolution of scientific production at the Department of Biochemistry over the years were obtained from the Department of Biochemistry's administrative records. Important dates were registered, including the opening of the Department of Biochemistry's master's (MSc) and $\mathrm{PhD}$ programs, the arrival of important researchers, major financial grants and others. We also obtained data on the establishment of national scientific policies (such as financial stimuli for productive researchers and evaluation systems of postgraduate programs) from the national research (CNPq) and superior education (CAPES) agencies.

To assess the contribution of the Department of Biochemistry for the scientific production of the
UFRGS, we used the SCOPUS base to obtain data from indexed papers produced.

\section{RESULTS}

From 1971 to 2007, the total scientific output of the Department of Biochemistry in periodicals amounted to 1534 articles, of which 1247 were indexed by the ISI. The scientific production by the Department of Biochemistry steadily grew from 1977 onwards, and sharply rose in the mid-1990s, with the number of indexed articles per year quadrupling between 1995 and 2007 (Fig. 2). Meanwhile, non-indexed scientific production (which still accounts for a large part of scientific output in Brazil, especially in smaller centers) remained in a low level throughout the period.

In order to analyze if the quantitative growth of the Department of Biochemistry's production was accompanied by an increase in its visibility, we analyzed the impact of indexed articles published in the period. Despite the increase in the number of published articles in the last decade, the mean impact factors remained relatively stable after 1990 . The peak in mean impact factors was actually reached in the 1980s (data not shown), but this was mostly due to a relatively small number of articles in high-visibility journals by the main researcher in the Department of Biochemistry at the time, in a period when total productivity was low, leading to a high average impact. However, the sharp increase in the number of articles was accompanied by an increase in the cumulative impact factor of published articles over the past decade (Fig. 3).

Figure 4 shows that the increase of productivity cannot be attributed to an increase in the size of its faculty, since the number of faculty members remained relatively stable (Fig. 4A), with the rise in productivity in recent years being due to an increase in the mean number of articles per faculty member (Fig. 4A insert).

This increasing qualification faculty was accompanied by a significant increase in the number of postgraduate theses produced in the Department of Biochemistry (Fig. 4B).

Since the creation and growth of new research groups are seen as important factors in the growth of the Brazilian research activity (Leta et al. 1998), we decided to analyze the research production of individual 


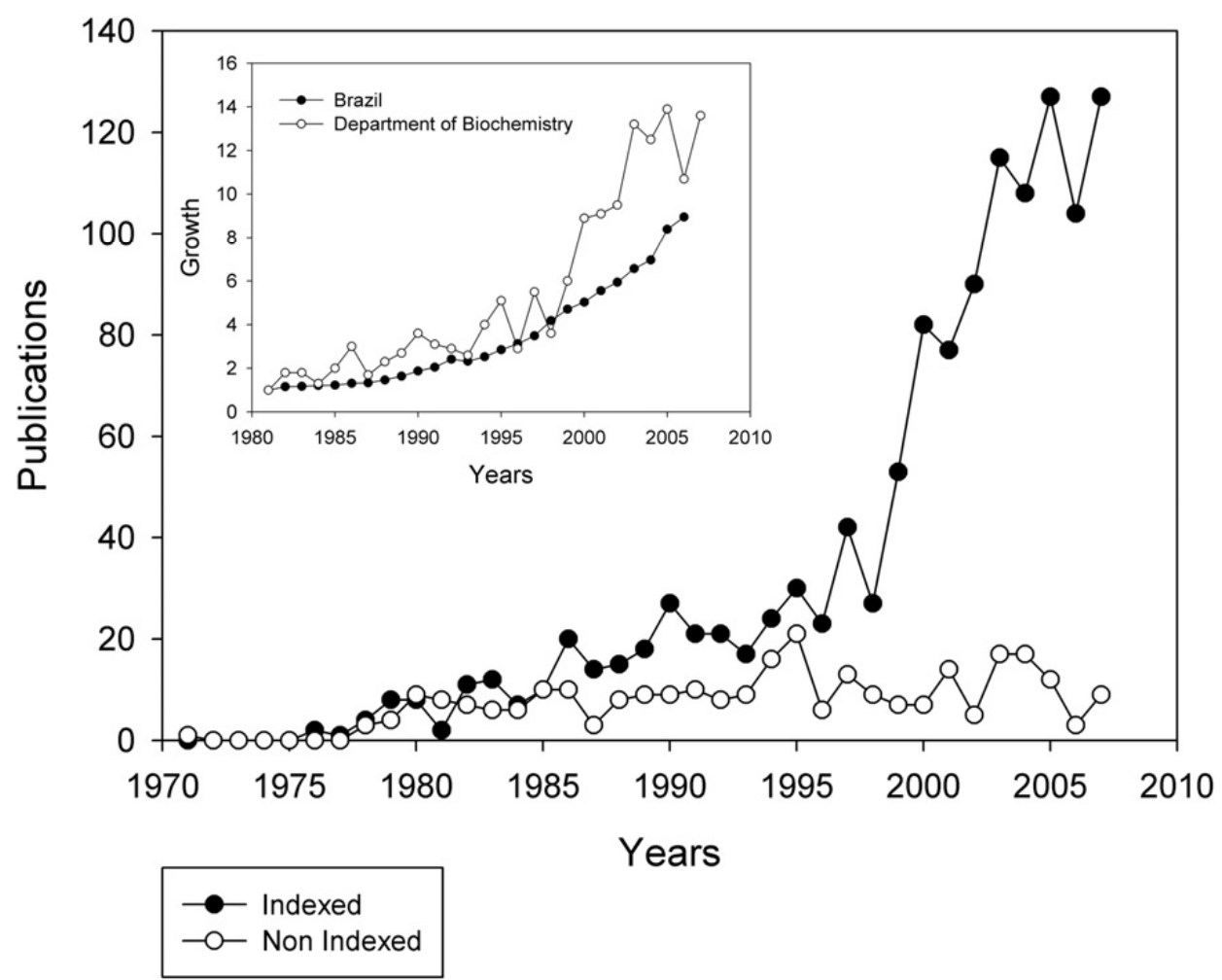

Fig. 2 - Scientific publications by faculty members at the Department of Biochemistry of Universidade Federal do Rio Grande do Sul from 1971 to 2007. The two lines indicate the number of articles published in ISI-indexed (black) and non-indexed (white) scientific journals in each year. Insert: Relative growth in the number of publications of the Department of Biochemistry (white) and in Brazilian (black) scientific publications from 1981 to 2007. Growth is expressed as the ratio of the number of articles in a given year to the number of articles in 1981.

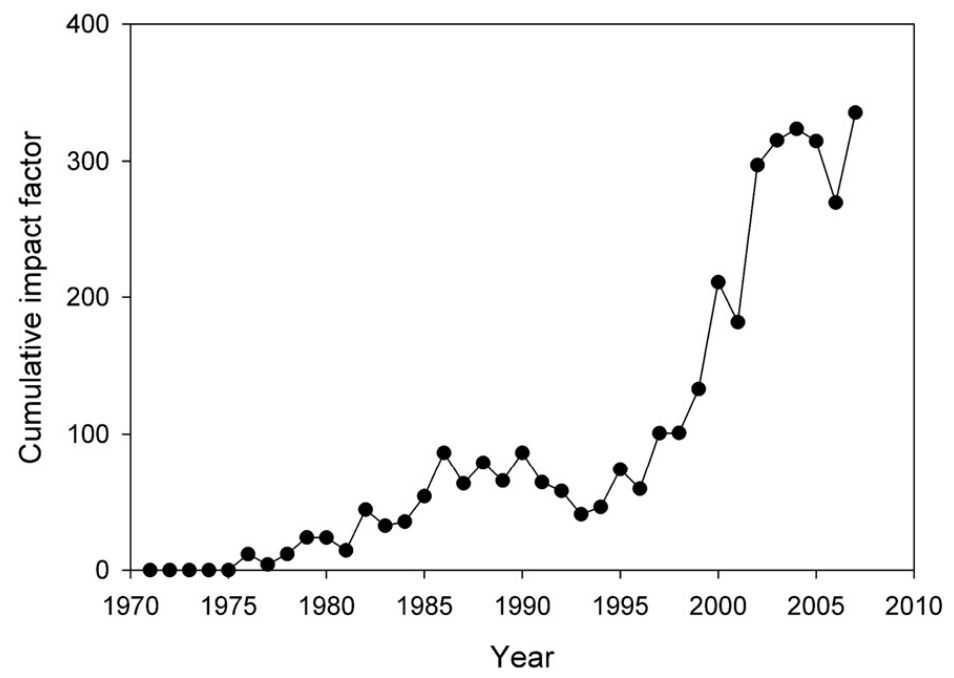

Fig. 3 - Cumulative impact factor of articles published from 1971 to 2007. The impact factor was obtained from Journal Citation Report (ISI). 


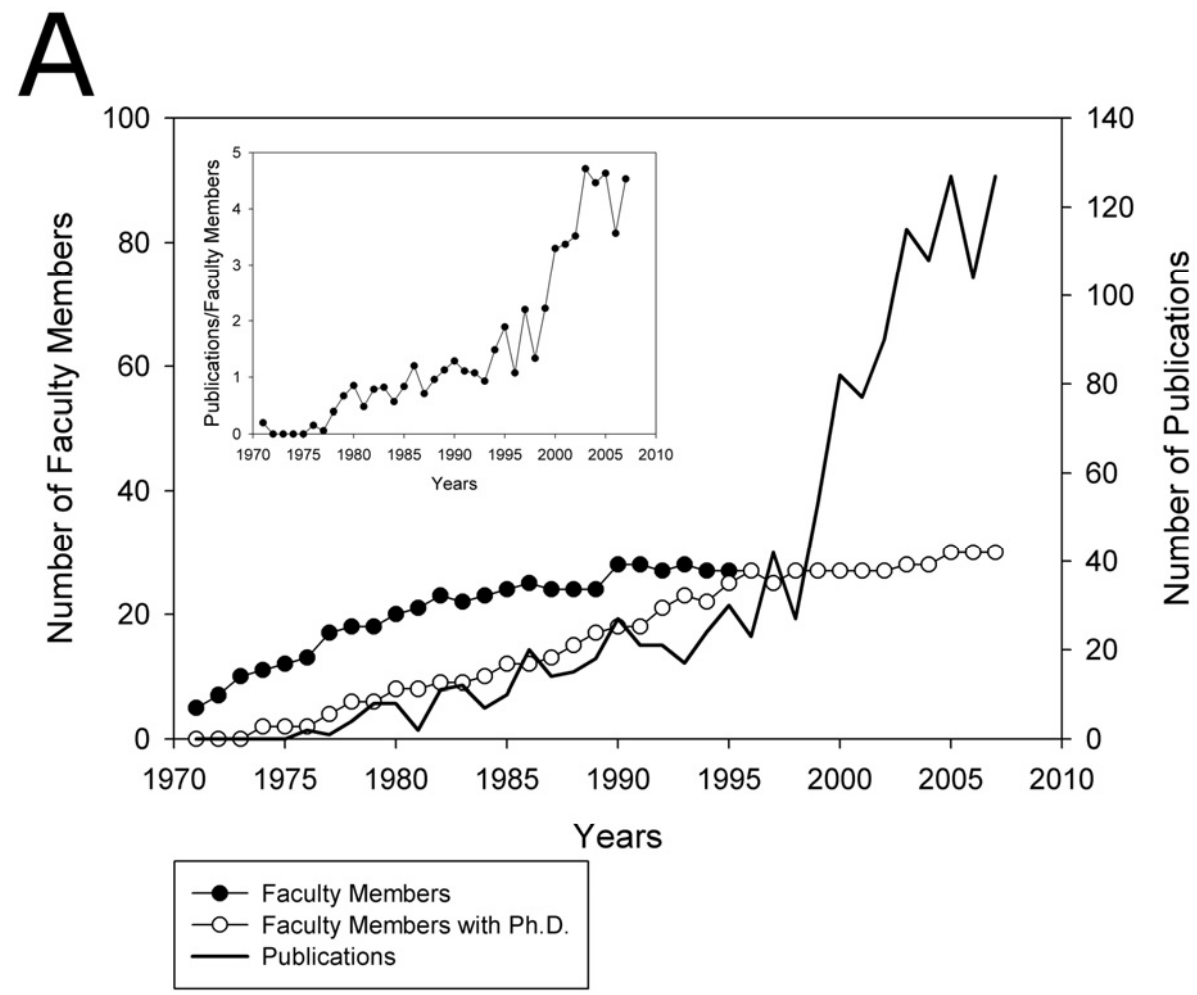

B

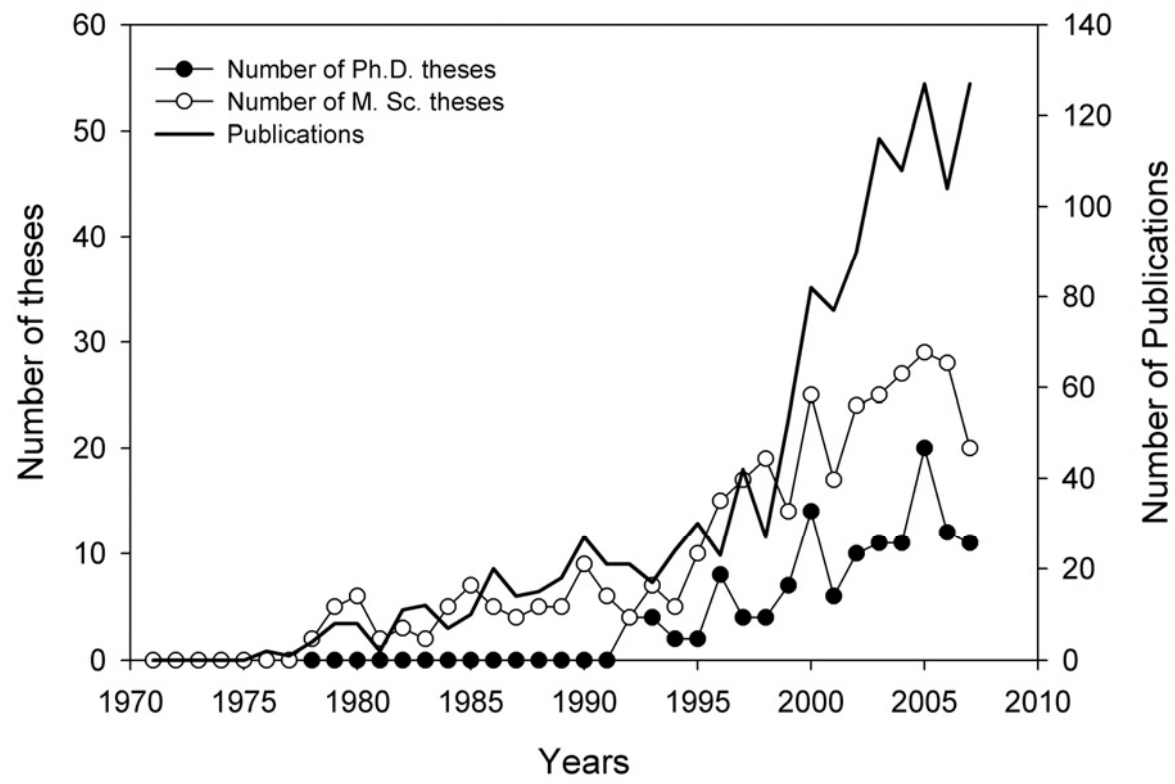

Fig. 4 - (A) Total number of faculty members (black) and number of faculty members with a $\mathrm{PhD}$ (white) at the Department of Biochemistry at Universidade Federal do Rio Grande do Sul from 1971 to 2007. The number of scientific publications in each year, as seen in Figure 1, is also plotted with the scale on the right-hand side for comparison. Insert: Mean number of publications in scientific journals per faculty members for every year between 1971 and 2007. (B) Number of MSc (white) and PhD (black) theses produced every year from 1971 to 2005 at the Department of Biochemistry of Universidade Federal do Rio Grande do Sul from 1971-2007. The number of scientific publications in each year, as seen in Figure 2, is also plotted with the scale on the right-hand side for comparison. 
researchers within the Department of Biochemistry's faculty over the years to try to visualize this trend. The scientific output of several research groups in the Department of Biochemistry grew over time (Fig. 5).

In order to correlate the temporal profile of the Department of Biochemistry's growth with important events in its history and in the history of the country, we listed some of these events in a chronological faction on Table I. Important events in this list include the arrival of abroad experienced researchers, the creation of the Department of Biochemistry's MSc and $\mathrm{PhD}$ programs, major research institutional grants, national productivity stimuli through the institution of personal grants for active researchers, and the current model of evaluation of postgraduate programs (heavily based on research output).

Finally, to identify the contribution of the Department of Biochemistry for the scientific production in the UFRGS, we compared the amount of publications generated by both institutions from 1970 to 2007 (Table II).

\section{DISCUSSION}

The first evident conclusion to be drawn for our study is the fact that the growth of scientific productivity in the Department of Biochemistry at the UFRGS over the years correlates well with that of the Brazilian science as a whole, at least temporally, with a slow increase in the 1970s and 1980s being followed by a rapid rise from the 1990s ongoing. This seems to be an indication that external factors, such as the switch in academic mentality and in national policies to try to favor research activity in public universities, can account for at least part of this growth. This includes the crescent value attributed to a researcher's publications in the distribution of scholarships, research grants and faculty positions, as well as the evaluation of postgraduate programs according to their scientific productivity.

Nevertheless, there are some differences between the Department of Biochemistry in our study and the national research profile. First of all, the relative increase in productivity in the Department of Biochemistry at the UFRGS is well over the national average (Fig. 2). A second difference from the national profile is the clear privileging of indexed, international, English language journals over national, Portuguese lan- guage periodicals, a pattern divergent to that observed in much of the country (Leta et al. 2001, Mendonça de Araújo et al. 2005, Leta et al. 2006). This internationally minded pattern, however, seems to predominate in some research centers in Brazil, and has been clearly on the rise in recent years (Mendonça de Araújo et al. 2005). The fact that most of the Department of Biochemistry's productivity is still aimed at low and medium impact journals, however, is in keeping with the national profile of a greater increase in the quantity of publications than in their visibility (Leta et al. 2006). This could be due to the fact that, although the Brazilian public policy has undoubtedly favored high numbers of publications in evaluating researchers and programs, stimuli for research quality and visibility, such as the measurement of citations and impact factors of publications, have been slower to come, and remains a challenge for coming years.

One of the most important observations of our study is that a steep rise in productivity was obtained without an increase in faculty members. A similar trend was shown for Brazilian public universities as a whole, in which scientific productivity virtually doubled between 1995 and 2000, while the increase in faculty members was insignificant (1.4\%) in the same period (Velloso et al. 2004). On the other hand, the qualification of the Department of Biochemistry's faculty (as measured by the proportion of faculty members with a $\mathrm{PhD}$ ), and especially the increase in the number of postgraduate students throughout the years, seem to present a better temporal correlation with the Department of Biochemistry's increase in productivity, and probably account for a significant part of it.

The importance of the formation of human resources on the Brazilian science in Brazil, especially through the establishment of postgraduate programs, has been previously studied (Leta et al. 1998), and an increase in scientific production has been shown to correlate with an increase in the number of postgraduate scholarships, even in times that research grants have not significantly increased (Leta et al. 1998, De Meis et al. 2003a). The increasing qualification of faculty members of the Department of Biochemistry at the UFRGS could be related to the increase in productivity, as the number of faculty members with a PhD in- 


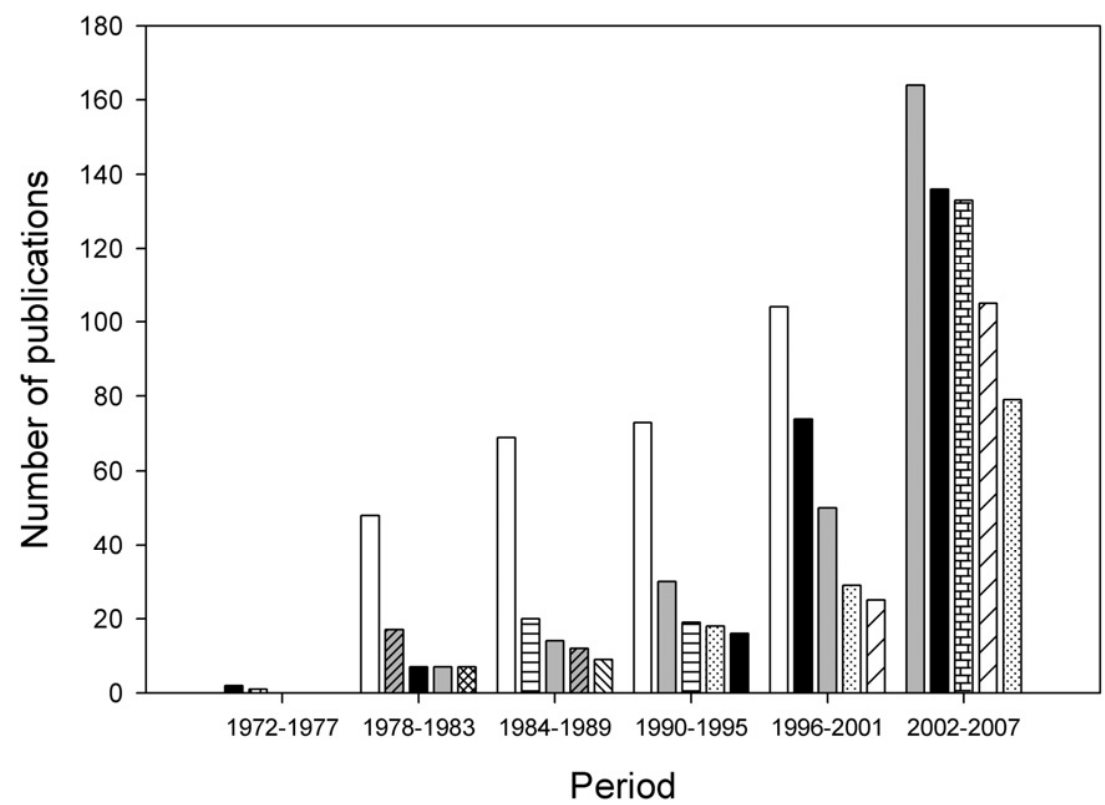

Fig. 5 - Number of publications at Department of Biochemistry by the 5 most productive faculty members. The data were expressed as number of publications from 1971 to 2007 grouped in 5-year periods. Each individual researcher is represented by a different bar pattern throughout the graph. Not all faculty members have their production depicted in every period, as the most productive researchers vary from period to period.

TABLE I

Landmark dates in the history of the Department of Biochemistry at the Universidade Federal do Rio Grande do Sul and in the recent history of the Brazilian science.

\begin{tabular}{c|l}
\hline Year & \multicolumn{1}{c}{ Event } \\
\hline 1971 & Foundation of the Department of Biochemistry at the UFRGS \\
1976 & Arrival of the $1^{\text {st }}$ senior professor (from Argentina) \\
1977 & Opening of postgraduate MSc program \\
1983 & Collaboration with another public university for the institution of a collective PhD program \\
1986 & Arrival of the $2^{\text {nd }}$ senior professor (from England) \\
1990 s & Institution of personal financial grants for active researchers \\
1992 & Opening of the Department of Biochemistry's own PhD program \\
1993 & The $1^{\text {st }}$ Study and Project Financing agency (FINEP) grant \\
1996 & The $2^{\text {nd }}$ FINEP grant; the $1^{\text {st }}$ National Support Program for Nuclei of Excellence (PRONEX) grant \\
1997 & Opening of the department's new headquarters \\
1998 & Start of the current national evaluation model for postgraduate courses by CAPES \\
2004 & The $3^{\text {rd }}$ FINEP (obtained through the Basic Health Sciences sector of the UFRGS) \\
2005 & The $2^{\text {nd }}$ PRONEX grant \\
2006 & IBN.Net \\
\hline
\end{tabular}

creased steadily from around $10 \%$ in the 1970 s to $100 \%$ in 1995 (coincidently, the year when the steep rise in productivity begins). This increasing in the qualification of faculty members was accompanied by a significant increase in the number of postgraduate theses produced in the Department of Biochemistry (Fig. 4B).
In the case of our Department of Biochemistry, the argument to be made in favor of the increase in postgraduate students is a particularly strong one. This was driven by the creation of its postgraduate master's and $\mathrm{PhD}$ programs in 1977 and 1992, respectively, and favored by the increase in research activity and in the 
TABLE II

Publication number from the Department of Biochemistry versus publication number from UFRGS.

\begin{tabular}{l|c|c|c||c|c|c|c}
\hline Year & $\begin{array}{c}\text { Department's } \\
\text { publications }\end{array}$ & $\begin{array}{c}\text { UFRGS's } \\
\text { publications }\end{array}$ & $\%$ & Year & $\begin{array}{c}\text { Department's } \\
\text { publications }\end{array}$ & $\begin{array}{c}\text { UFRGS's } \\
\text { publications }\end{array}$ & $\%$ \\
\hline $\mathbf{1 9 7 1}$ & 0 & 5 & 0.0 & $\mathbf{1 9 9 0}$ & 27 & 89 & 30.3 \\
$\mathbf{1 9 7 2}$ & 0 & 9 & 0.0 & $\mathbf{1 9 9 1}$ & 21 & 108 & 19.4 \\
$\mathbf{1 9 7 3}$ & 0 & 11 & 0.0 & $\mathbf{1 9 9 2}$ & 21 & 118 & 17.8 \\
$\mathbf{1 9 7 4}$ & 0 & 13 & 0.0 & $\mathbf{1 9 9 3}$ & 17 & 121 & 14.0 \\
$\mathbf{1 9 7 5}$ & 0 & 24 & 0.0 & $\mathbf{1 9 9 4}$ & 24 & 162 & 14.8 \\
$\mathbf{1 9 7 6}$ & 02 & 20 & 10.0 & $\mathbf{1 9 9 5}$ & 30 & 170 & 17.6 \\
$\mathbf{1 9 7 7}$ & 01 & 19 & 5.3 & $\mathbf{1 9 9 6}$ & 23 & 344 & 6.7 \\
$\mathbf{1 9 7 8}$ & 04 & 28 & 14.3 & $\mathbf{1 9 9 7}$ & 42 & 426 & 9.9 \\
$\mathbf{1 9 7 9}$ & 08 & 29 & 27.6 & $\mathbf{1 9 9 8}$ & 27 & 440 & 6.1 \\
$\mathbf{1 9 8 0}$ & 08 & 36 & 22.2 & $\mathbf{1 9 9 9}$ & 53 & 471 & 11.3 \\
$\mathbf{1 9 8 1}$ & 02 & 34 & 5.9 & $\mathbf{2 0 0 0}$ & 82 & 522 & 15.7 \\
$\mathbf{1 9 8 2}$ & 11 & 46 & 23.9 & $\mathbf{2 0 0 1}$ & 77 & 538 & 14.3 \\
$\mathbf{1 9 8 3}$ & 12 & 39 & 30.8 & $\mathbf{2 0 0 2}$ & 90 & 625 & 14.4 \\
$\mathbf{1 9 8 4}$ & 07 & 47 & 14.9 & $\mathbf{2 0 0 3}$ & 115 & 709 & 16.2 \\
$\mathbf{1 9 8 5}$ & 10 & 65 & 15.4 & $\mathbf{2 0 0 4}$ & 108 & 845 & 12.8 \\
$\mathbf{1 9 8 6}$ & 20 & 51 & 39.2 & $\mathbf{2 0 0 5}$ & 127 & 1290 & 9.8 \\
$\mathbf{1 9 8 7}$ & 14 & 53 & 26.4 & $\mathbf{2 0 0 6}$ & 104 & 1464 & 7.1 \\
$\mathbf{1 9 8 8}$ & 15 & 68 & 22.1 & $\mathbf{2 0 0 7}$ & 127 & 1525 & 8.3 \\
$\mathbf{1 9 8 9}$ & 18 & 85 & 21.2 & & & & \\
\hline
\end{tabular}

capability of the faculty in supervising students. Moreover, it also closely accompanies the increase in the department's scientific output, a relation that has also been shown to occur between the total Brazilian scientific output and the number of postgraduate students (Leta et al. 1998).

Since the creation and growth of new research groups seem to be an important factor in the growth of the Brazilian research activity (Leta et al. 1998), we decided to analyze the research production of individual researchers within the department's faculty over the years to try to visualize this trend. The scientific output of a number of research groups in the department grew over time (Fig. 5). However, the distribution of scientific production among faculty members significantly changed over time, from a scenario in which one senior researcher (white bar in the figure, who came from Argentina in 1976) dominated the Department of Biochemistry's research activity to one in which various researchers shared the department's productivity in a more equal fashion.
Then, an important factor in the growth of our Department of Biochemistry seems to have been the arrival of the abroad senior researchers. This has been advocated as a particularly effective way of driving scientific productivity in Brazil to the standards of the developed world, with reduced costs and "brain drain" when compared with the alternative of sending Brazilian students abroad (De Meis and Longo 1990). In the case of our Department of Biochemistry, the arrival of two well-established researchers helped the increase research not only through their own scientific output, but also through the qualification of their colleagues. This is clearly shown by the fact that, of the current faculty members of the department, 11 (33\%) had one of these two senior researchers as their $\mathrm{PhD}$ advisors. This spreading of knowledge can therefore probably account for the growth of new scientific groups and the more homogeneous distribution of scientific production in the department, as seen in Figure 5. The establishment of a larger number of productive research groups also promotes and increases the number of collaborations 
among researchers, helping to keep productivity on the rise.

In order to correlate the temporal profile of Department of Biochemistry's growth with important events in its history and in the history of the country, we listed some of these events in a chronological faction on Table I. Important events in this list include the arrival of abroad experienced researchers, the creation of the Department of Biochemistry's MSc and PhD programs, major research institutional grants, national productivity stimuli through the institution of personal grants for active researchers, and the current model of evaluation of postgraduate programs (heavily based on research output).

Along with the factors relating to the human resources discussed above, greater financial investments also seems to have played a role in the increase in the Department of Biochemistry's productivity. The first large institutional grants, for example, were obtained in the mid 1990s, just before the point in which scientific output began to rise more steeply. However, one should note that these grants were obtained through a scientific activity that was already on the rise at that time. As previously mentioned, this point in time also coincides with the establishment of national policies for stimulating research within universities, including the concession of financial rewards for productive research and the evaluation of scientific productivity for classifying postgraduate programs (Leta and De Meis 1996). This switch in national policy also led to changes in internal policies within the Department of Biochemistry at the UFRGS in order to stimulate research, including the requirement of at least one indexed publication as a first author for students in order to earn a $\mathrm{PhD}$, as well as a heavy increase in the importance of research publications in classifying both students applying for postgraduate scholarships and researchers applying for faculty positions.

We also wanted to assess how the Department of Biochemistry contributes to the scientific production of the UFRGS concerning indexed articles. We observed that this contribution was higher in some periods, specially around the 1980 's, but this pattern has changed once since 1995 until now this participation was established around $10 \%-12 \%$ (Table II). It is also possible that factors like higher impositions from foment organs and evaluations instated by CNPq and CAPES (since 1995) have motivated other UFRGS's departments to publish their work in international data literature. Then, although the Department of Biochemistry presents an annual rise in the amount of indexed papers, accounting for a significant contribution, its participation has been stable concerning percentages during the period of 1995 to 2007.

Therefore, analyzing this data as a whole, it appears that the rise of productivity in our case is tightly linked to: (i) the investment in human resources, manifested by the increase in the number of students, qualification of faculty members and the arrival of senior researchers, and (ii) the stimulation of productivity by national and local policies, which increasingly value of scientific publications in the distribution of resources and selection of personnel for postgraduate and faculty positions. Although it is unclear whether this can be generalized to the Brazilian science as a whole, a similar pattern probably holds true for most of the countries' reference research centers of excellence, which account for most of the national productivity (Leta and De Meis 1996, Velloso et al. 2004), and can therefore might explains to a large extent, the increase in Brazil's share of international scientific activity.

\section{ACKNOWLEDGMENTS}

This work was supported by the Brazilian funding agencies Coordenação de Aperfeiçoamento de Pessoal de Nível Superior (CAPES), Financiadora de Estudos e Projetos (FINEP) and Instituto Nacional de Ciência e Tecnologia em Excitotoxicidade e Neuroproteção (INCTEN).

\section{RESUMO}

A atividade científica no Brasil apresentou um crescimento acelerado nas últimas décadas, com um aumento na produtividade que ultrapassou os valores médios internacionais. Este crescimento tem ocorrido através dos centros de excelência em pesquisa nas Universidades Públicas, as quais são responsáveis pela maior parte da produção científica do país. O presente estudo tem como objetivo avaliar a produção do Departamento de Bioquímica de uma grande universidade pública do sul do Brasil (Universidade Federal do Rio Grande do Sul - UFRGS), 
bem como identificar os fatores internos e externos que influenciaram este perfil crescente de produção. Foi realizada uma análise histórica da produção científica do Departamento, a qual representa uma parte considerável da produção científica da Universidade. Ao enfocar a evolução temporal do seu crescimento e o estudo das correlações entre a produção científica e eventos importantes na história do Departamento de Bioquímica e das políticas científicas brasileiras, podemos concluir que os fatores internos (como a criação de um programa de pós-graduação, a colaboração entre pesquisadores, a experiência no exterior por parte dos pesquisadores, a qualificação dos docentes) e fatores externos (como os investimentos na formação de pós-graduandos, o estabelecimento de políticas nacionais científicas, tais como estímulos financeiros para os pesquisadores produtivos e sistemas de avaliação) influenciam a produção científica no Brasil.

Palavras-chave: produtividade científica, perfil de crescimento científico, Bioquímica, UFRGS.

\section{REFERENCES}

AYALA FJ. 1995. Science in Latin America. Science 267: 826-827.

DE MEIs L. 2003b. Impact factors: just part of a research treadmill. Nature 424: 723.

DE MEIs L AND Longo PH. 1990. The training of Brazilian Biochemists in Brazil and in Developed Countries: Costs and benefits, Biochem Educ 18: 182-188.

De Meis L, Velloso A, Lannes D, Carmo MS and De MEIS C. 2003a. The growing competition in Brazilian science: rites of passage, stress and burnout, Braz J Med Biol Res 36: 1135-1141.
Glanzel W, Leta J And Thus B. 2006. Science in Brazil. Part 1: A macro-level comparative study. Scientometrics 67: 67-86.

Leta J AND De Meis L. 1996. A profile of science in Brazil. Scientometrics 35: 33-44.

Leta J, GLANZEL W AND Thus B. 2006. Science in Brazil. Part 2: Sectoral and institutional research profiles. Scientometrics 67: 87-105.

Leta J, Jaques R, Figueira I AND De Meis L. 2001. Central visibility of Brazilian psychiatric publications from 1981 to 1995 . Scientometrics 50: 241-254.

Leta J, Lannes D and De Meis L. 1998. Human resources and scientific productivity in Brazil. Scientometrics 41: 313-324.

Mendonça de Araújo K, Mourão PAS and Leta J. 2005. Balance between education- and research-oriented publications from a Brazilian University Hospital. Braz J Med Biol Res 38: 1285-1291.

PORTAL http://www.capes.gov.br acessado em setembro de 2009.

SCHWARTZMAN S. 2004. Equity, quality and relevance in higher education in Brazil. An Acad Bras Cienc 76: 173188

Velloso A, Lannes D and De Meis L. 2004. Concentration of Science in Brazilian governmental universities. Scientometrics 21: 207-220. 